\title{
EEC syndrome without ectrodactyly: report of two new families
}

\author{
J P Fryns, E Legius, A M Dereymaeker, $H$ Van den Berghe
}

\begin{abstract}
In this report we describe two families with variable manifestations of the EEC syndrome. The findings in these families confirm that no symptom is obligatory for the diagnosis of EEC syndrome. In the absence of cleft lip/palate, EEC patients have a characteristic facial morphology with maxillary hypoplasia, short philtrum, and broad nasal tip.
\end{abstract}

After the first descriptions by Eckoldt and Martens, ${ }^{1}$ Rüdiger $e t a l^{2}$ introduced the term EEC syndrome to designate the triad of ectrodactyly (split hand/foot deformity), cleft lip/palate, and ectodermal dysplasia (anomalies of the hair, teeth, nails, nasolacrimal ducts, and sweat glands). Autosomal dominant inheritance has largely been documented, ${ }^{34}$ as well as variability in expression..$^{5-7}$ Recently, Küster et $a l^{8}$ and Majewski and Küster ${ }^{9}$ reported three families with variable expression of the EEC syndrome and stated that ectrodactyly is not an obligatory symptom.

Centre for Human Genetics, University of Leuven, Herestraat 49, 3000 Leuven, Belgium.

J P Fryns, E Legius, A M Dereymaeker, H Van den Berghe

Correspondence to Professor Fryns.

Received for publication 6 August 1989.

Revised version accepted for publication 29 September 1989.

\section{Case reports}

FAMILY 1

This family came to our attention after the birth of two sisters with a variable pattern of limb defects.

The older daughter was 3 years old at the time of examination. She had complete cutaneous syndactyly $3 / 4$ on the left hand, and a split hand deformity with absence of the middle finger and cutaneous syndactyly $1 / 2$ on the right hand (fig 1). Except for bilateral brachymetatarsy $4 / 5$, both feet were normal. She had fine, silver-blond hair but no other signs of ectodermal dysplasia. The face was peculiar with a short philtrum, maxillary hypoplasia, and a broad nasal tip. Physical and psychomotor development were normal.

Her 1 year old sister had an atypical lobster claw deformity of both hands; the phalanges of the third fingers were absent bilaterally with hypoplasia of the third metacarpal (fig 2). There was, in addition, mild cutaneous syndactyly $1 / 2$ and camptodactyly of the second to fourth fingers. On the right foot an accessory rudimentary toe was present between the first and second toes without extra metatarsals (fig 3). The nails and hair were normal. She had the same facial characteristics as found in her older sister, that is, short philtrum, maxillary hypoplasia, and broad nasal tip.

Clinical examination of their 30 year old mother showed the same facial appearance as her two

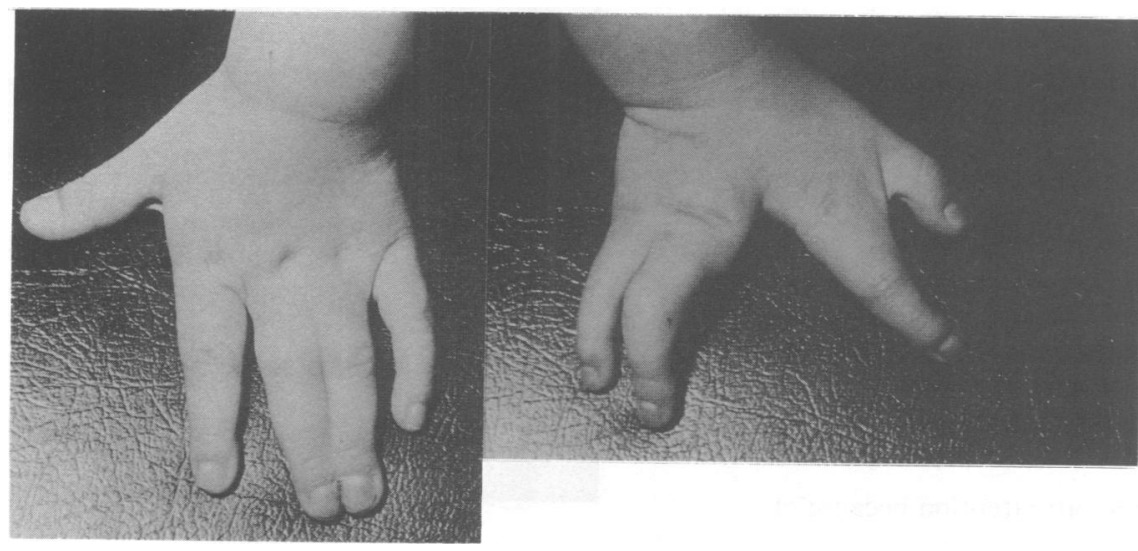

Figure I The hand anomalies in the older child of the first family: cutaneous syndactyly 3/4 in the left hand and split hand deformity in the right hand. 


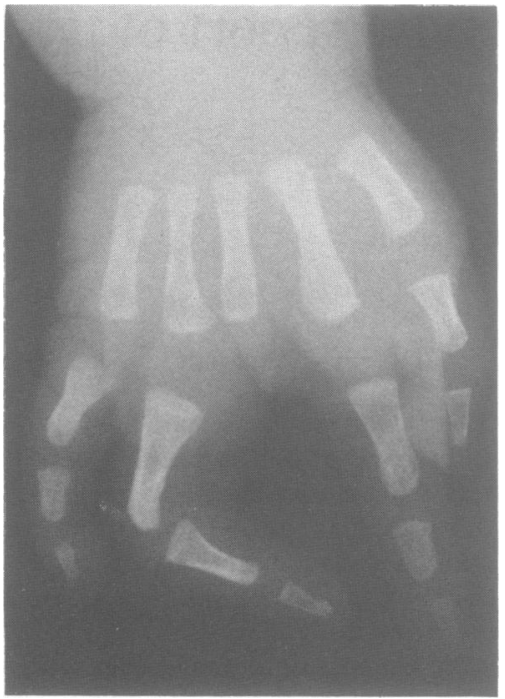

Figure 2 Bilateral split hand deformity in the younger sister of the first family.

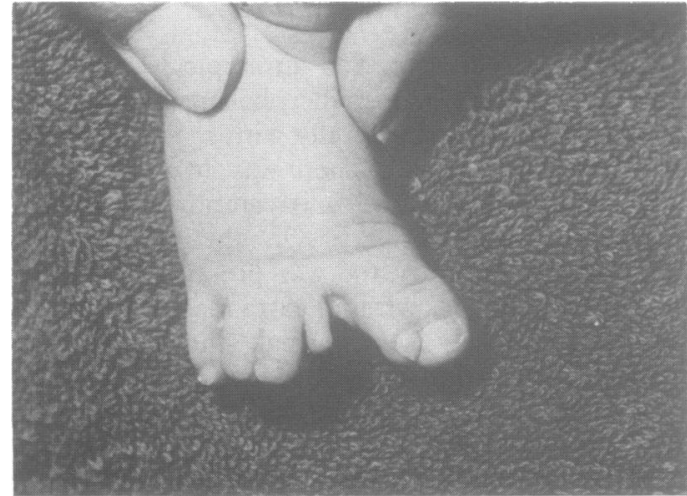

Figure 3 Accessory rudimentary toe between toes 2 and 3 of the right foot of the younger child of the first family.

daughters. She had fine, silver-blond hair and all the finger nails were dystrophic, but the hands and feet were otherwise normal. The teeth were very carious and she had had a complete dental prosthesis from the age of 16 years.

She was the oldest child in a family of three children. Clinical examination of both parents and the younger brother and sister was normal. None of them had anomalies of the hands or feet, or ectodermal dysplasia, or similar facial changes.

FAMILY 2

The second family came to our attention because of a split hand and foot deformity in the son. He was born
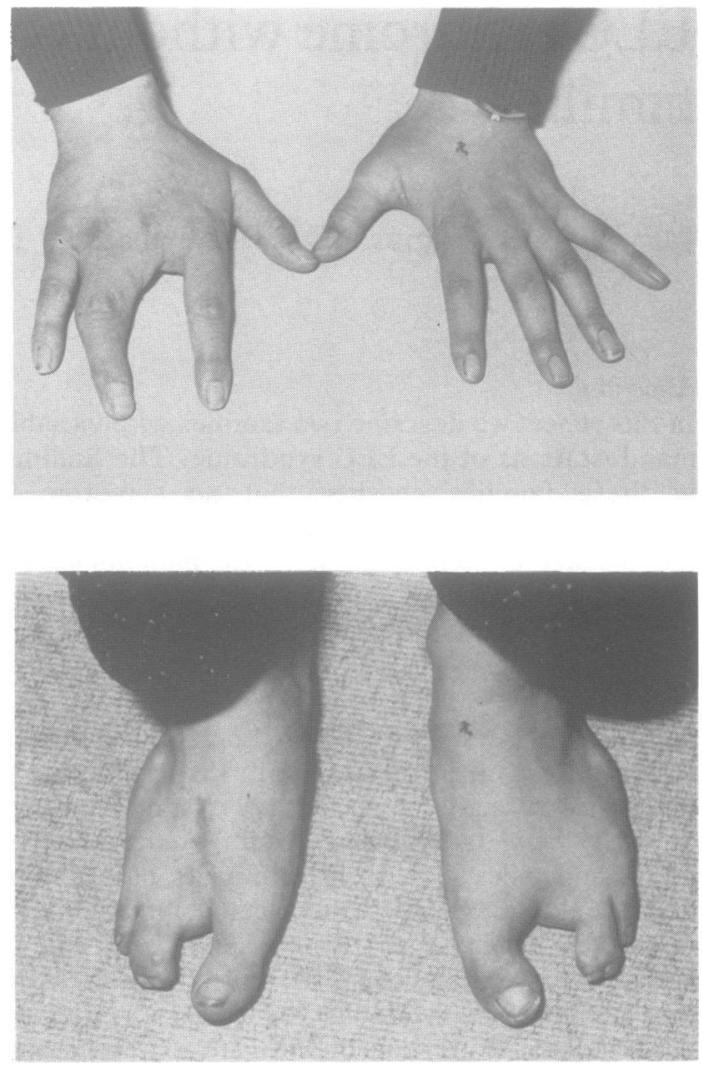

Figure 4 Atypical split hand deformity and bilateral split foot deformity in the son of the second family.

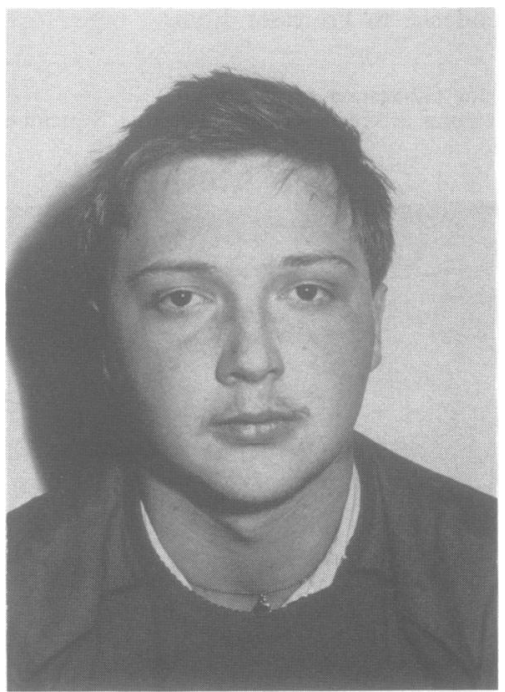

Figure 5 Face of the son of the second family. 
at a gestational age of 35 weeks after caesarian section because of horizontal fetal presentation and rupture of membranes. He had bilateral split foot deformity with syndactyly $3 / 4$. Unilateral split hand was present on the right, with fusion of the proximal phalanges of the third and fourth fingers. The middle and distal phalanges of the third finger were absent (fig 4). The left hand was completely normal. When he grew older, hypodontia became evident. He had fine, blond hair, but skin, nails, palate, and facial morphology were normal (fig 5).

The sister of the proband was reported to be born as a 'collodion baby'. She subsequently developed a very dry, scaly skin, dystrophic nails, and marked hypodontia (fig 6). She had fine, blond hair, small

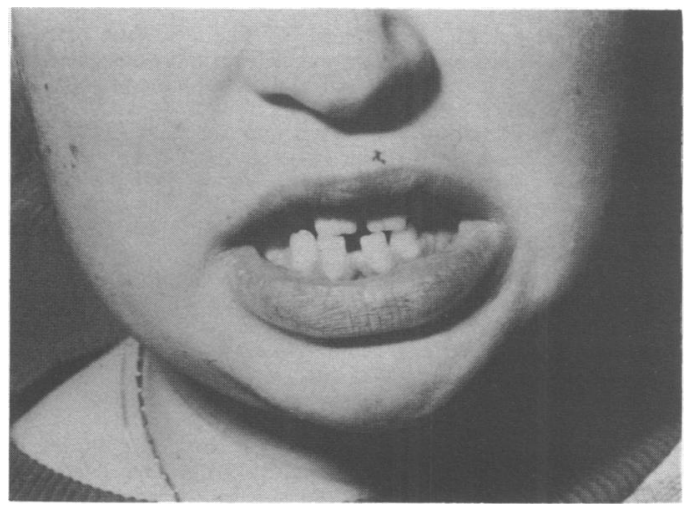

Figure 6 Hypodontia in the daughter of the second family.

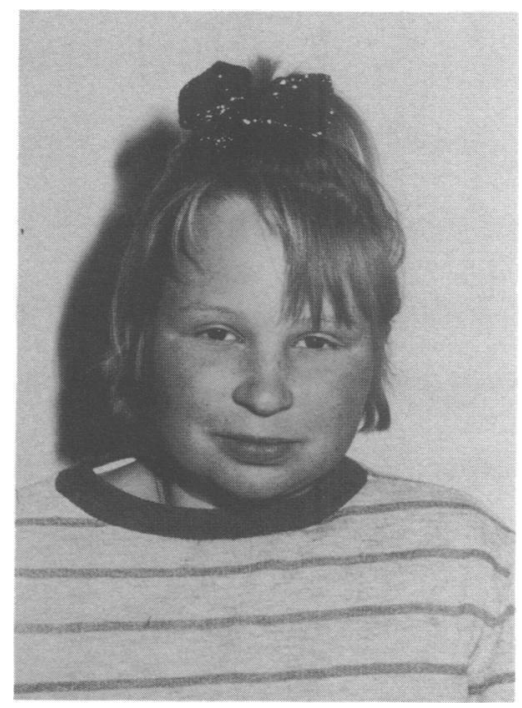

Figure 7 Face of the daughter of the second family.

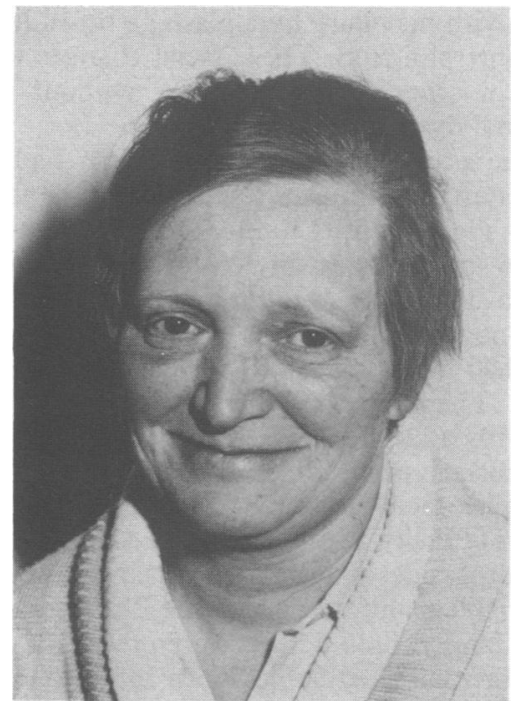

Figure 8 Face of the mother of the second family. Note scanty hair, maxillary hvpoplasia, and short philtrum.

palpebral fissures, and a broad nasal tip (fig 7). Her hands, feet, and palate were normal.

The mother of these sibs suffered from severe ectodermal dysplasia. Alopecia started at the age of 18 years and she needed a complete dental prosthesis at the age of 16. All nails were dystrophic and the skin was dry, erythematous, and scaly. Maxillary hypoplasia and a short philtrum were evident (fig 8), but her hands, feet, and palate were normal. She reported that her mother and her maternal grandmother had had the same skin, tooth, nail, and hair problems as she had.

\section{Discussion}

The index patients of the two families in this report present a variable pattern of limb defects. In the first family, typical ectrodactyly, as described in the EEC syndrome, was present in both hands of the younger child. In the older child, however, a split hand deformity was present only in the right hand combined with complete cutaneous syndactyly $2 / 3$ on the left hand. In both children, the foot anomalies were minimal except for the small accessory toe between toes 2 and 3 on the right foot of the younger child. Signs of ectodermal dysplasia were limited to fine, silver-blond hair in the younger child. In contrast, the mother had no hand or foot anomalies, but the ectodermal changes were much more evident: loss of permanent dentition before the age of 16 , fine, silverblond hair, and dystrophic nails. None of the three patients had cleft lipcleft palate, but their faces were 
peculiar with maxillary hypoplasia, a broad nasal tip, and a short philtrum. These facial changes were not present in other family members without signs of ectodermal dysplasia or ectrodactyly.

In the second family, only the son had typical ectrodactyly of both feet. The unilateral hand abnormality is identical to the unilateral hand abnormality of case 6 in the report of Küster et al. ${ }^{8}$ Ectodermal dysplasia in the son was limited to hypodontia and fine, blond hair. However, his sister and especially his mother had more severe ectodermal dysplasia, but no clefting. The mother had marked maxillary hypoplasia with a short philtrum and the daughter only had a broad nasal tip.

A similar facial appearance was noted in attected members of the two families reported by Küster et al. ${ }^{8}$ These authors described eight cases from two families with variable manifestations of the EEC syndrome. In the first family, limb defects were present in only one out of three affected subjects. In the second family, limb defects were noted in three members and cleft lip/cleft palate in two of the five affected patients.

Majewski and Küster ${ }^{9}$ reported another family with oligosymptomatic EEC syndrome. Ectrodactyly, submucous cleft palate, and carious teeth were present in the mother. The son had cutaneous syndactyly and hypoplastic phalanges on the feet, and the daughter had a stiff thumb. They calculated the penetrance of typical EEC syndrome in 13 reported families to be reduced to about $78 \%$.

Judging from the experience in these families and the present observations, the EEC syndrome may show a much larger variability in expression than previously recognised. Ectrodactyly is not an obligatory symptom ${ }^{89}$ and cleft lip/cleft palate may also be absent. In EEC patients with absence of the lobster claw defect, a characteristic facial morphology can be present with relative midfacial hypoplasia, characteristic short philtrum, and broad nasal tip. Special attention to these facial characteristics should be given in the clinical evaluation of families with this rare syndrome.

1 Eckoldt JG, Martens FH. Ueber eine sehr Complicirte Hasenscharte oder einen sogenannten Wolfsrachen mit einer an demselben Subjekte befindlichen merkwürdigen Misstaltung der Hände und Füsse. Leipzig: Steinacker, 1804.

2 Rüdiger RA, Haase W, Passarge E. Association of ectrodactyly, ectodermal dysplasia, and cleft lip-palate. Am $\mathcal{f}$ Dis Child 1970;120:160-3.

3 Brill CB, Hsu LYF, Hirschhorn K. The syndrome of ectrodactyly, ectodermal dysplasia and cleft lip and palate: report of a family demonstrating a dominant inheritance pattern. Clin Genet 1972;3:295-302.

4 Pfeiffer RA, Verbeck C. Spalthand und Spaltfuss, ektodermale Dysplasie und Lippen-Kiefer-Gaumen-Spalate: ein autosomaldominant vererbtes Syndrom. Z Kinderheilkd 1973;115:235-44.

5 Bixler D, Spivack J, Bennett J, Christian JC. The ectrodactylyectodermal dysplasia-clefting (EEC) syndrome. Clin Genet 1972;3:43-51.

6 Lurie IV, Lazyuk GI, Usova YI. Genetic characteristics of the EEC syndrome. Genetika 1976;12:125-31.

7 Penchaszadeh VB, de Negrotti TC. Ectrodactyly-ectodermal dysplasia-clefting (EEC) syndrome: dominant inheritance and variable expression. $\mathcal{F}$ Med Genet 1976;13:281-4.

8 Küster W, Majewski F, Meinecke P. EEC syndrome without ectrodactyly? Clin Genet 1985;28:130-5.

9 Majewski F, Küster W. EEC syndrome sine sine? Report of a family with oligosymptomatic EEC syndrome. Clin Genet 1988;33:69-72. 